\title{
Effect of carbon substrate materials as a Pt-Ru catalyst support on the performance of direct methanol fuel cells
}

\author{
Eunjoo Yoo ${ }^{\mathrm{a}}$, Tatsuhiro Okada ${ }^{\mathrm{b}}$, Tokushi Kizuka ${ }^{\mathrm{a}}$, Junji. Nakamura ${ }^{\mathrm{a} *}$
}

${ }^{\mathrm{a}}$ Graduate School of Pure and Applied Science, University of Tsukuba, Tsukuba, Ibaraki 305-8573, Japan

${ }^{b}$ National Institute of Advanced Industrial Science and Technology, Higashi 1-1-1, Central 5, Tsukuba, Ibaraki 305-8565, Japan

Keywords: Carbon nanotube; Platinum; Ruthenium; anode catalyst; direct methanol fuel cell

* Corresponding author. Tel. \& fax.: +81 29853 5279, E-mail address:

nakamura@ims.tsukuba.ac.jp 


\begin{abstract}
The support effect of carbon nanotubes (CNTs) for direct methanol fuel cell (DMFC) was studied using CNTs with and without defect preparation, carbon black, and fishbone-type CNTs. The Pt-Ru/defect-free CNTs afforded the highest catalytic activity of methanol oxidation reaction (MOR) in rotating disk electrode experiments and the highest performance as the anode catalysts in DMFC single cell tests with the one-half platinum loading compared to Pt-Ru/VulcanXC-72R. CO stripping voltammograms with Pt-Ru/defect-free CNTs also revealed the lowest CO oxidation potential among other Pt-Ru catalysts using different carbon support. It is thus considered that the carbon substrates significantly affect the CO oxidation activity of anode electrocatalysts in DMFC. This is ascribed to the geometrical effect that the flat interface between CNTs and metal catalysts has a unique feature, at which the electron transfer occurs, and this interface would modify the catalytic properties of Pt-Ru particles.
\end{abstract}




\section{Introduction}

Direct methanol fuel cell (DMFC) is one of the most promising devices for the nearest future energy sources. One of the major problems, however, is the poisoning of the anode catalyst by carbon monoxide and hence the slow kinetics of the anode methanol oxidation reaction (MOR). Binary Pt-Ru/carbon catalysts are extensively studied as a promising CO-tolerant anode catalyst in DMFC [1-3]. Specific activity of catalysts is strongly dependent on the catalysts size, size distribution and the support materials. Carbon black (CB) has been widely used as an electrocatalysts support because of good electronic conductivity, high surface area, and low cost. Recently, many nanostructured carbon materials with graphitic structure, such as carbon nanotubes (CNTs) and carbon nanofibers (CNFs) have been studied. Particularly, CNTs are of interest due to their unique electro and micro- and macro- structural characteristics [4-8]. Li et al. have reported that Pt-Ru supported on double-walled nanotubes (DWNTs) shows the highest specific activity for MOR and can reduce the Pt-Ru electrode loading to 83 \% when compared to Pt-Ru/VulcanXC-72R [9]. Kim et al. also have reported that a DMFC single cell with a cup-stacked CNT supported Pt-Ru anode catalysts showed nearly two times the maximum power density at $90{ }^{\circ} \mathrm{C}$ of a DMFC compared with a CB (VulcanXC-72R) supported Pt-Ru anode catalysts [10]. It is clearly suggested that CNTs are expected to be a good candidate as the support of DMFC electrocatalysts. In spite of this expectation, there are established no clear techniques for Pt-Ru/CNT preparation and the performance evaluation of DMFC with CNTs as substrate materials for the anode electrocatalysts.

In this paper, we report the electrochemical performances of Pt-Ru electrocatalysts supported on various carbon substrate materials. The catalysts prepared were tested for the methanol oxidation reaction (MOR) in $1 \mathrm{~mol} \mathrm{dm}^{-3} \mathrm{CH}_{3} \mathrm{OH}+0.05 \mathrm{~mol} \mathrm{dm}^{-3} \mathrm{H}_{2} \mathrm{SO}_{4}$ 
and for the performance of DMFC single cells. CO stripping voltammograms were studied to evaluate the CO poisoning and oxidation during the MOR.

\section{Experimental}

The CNTs used in this study were purchased from Shenjen Nanotech Co.Ltd, which were prepared by a catalytic decomposition method of hydrocarbons. BET specific surface area of the defect-free CNTs was $72.7 \mathrm{~m}^{2} \mathrm{~g}^{-1}$ with length of $10 \mu \mathrm{m}$, outer diameter of 20-50 nm, inner diameter of 3-10 nm, and wall layers of 25-60. The metal particles contained in the CNTs as the synthesis catalyst during production were removed by washing in concentrated $\mathrm{HNO}_{3}(14 \mathrm{~N})$ at room temperature for $2 \mathrm{~h}$ followed by ultrasonication in concentrated $\mathrm{HNO}_{3}$. After subsequent washing with distilled water, the CNTs were dried at $100{ }^{\circ} \mathrm{C}$ in air. In order to examine the effect of a carbon surface finishing, defects were intentionally introduced by oxidation in air. We have reported earlier that the partial oxidation of CNTs by air brought about opening of the tube ends and creation of the defects at the outer wall, which the layers of the tube were partially etched and holes of 10-30 nm size were formed [11]. For this purpose defect-free CNTs were heated in a quartz tube reactor with flowing air $\left(10 \mathrm{~mL} \mathrm{~min}^{-1}\right)$ to $600{ }^{\circ} \mathrm{C}$. The fishbone-type CNTs with length of $10 \mu \mathrm{m}$, diameter of $50-100 \mathrm{~nm}$ were also used to examine the surface effect of CNTs, where the carbon surface was not composed of flat graphene sheets, but of graphene edges. The fishbone-type CNTs are called cup-stacked-type CNTs, i.e., the cups made of graphene sheet are stacked together to form a tubular shape with internal canals ranging from 50 to $150 \mathrm{~nm}$ wide. The samples were pretreated in concentrated $\mathrm{HNO}_{3}$ at room temperature for $2 \mathrm{~h}$ before use.

$\mathrm{Pt}-\mathrm{Ru}$ catalysts were prepared from platinum(II)acetylacetonate, 
$\left[\mathrm{CH}_{3} \mathrm{COCH}=\mathrm{C}\left(\mathrm{O}^{-}\right)\right]_{2} \mathrm{Pt}$, and ruthenium(III)acetylacetonate, $\left[\mathrm{CH}_{3} \mathrm{COCH}=\mathrm{C}\left(\mathrm{O}^{-}\right)\right]_{3} \mathrm{Ru}$, by the following procedure. The carbon support (200 mg) was impregnated with $\left[\mathrm{CH}_{3} \mathrm{COCH}=\mathrm{C}(\mathrm{O}-)\right]_{2} \mathrm{Pt}(300 \mathrm{mg})$ and $\left[\mathrm{CH}_{3} \mathrm{COCH}=\mathrm{C}(\mathrm{O}-)\right]_{3} \mathrm{Ru}(200 \mathrm{mg})$ in $40 \mathrm{ml} \mathrm{THF}$ (tetrahydrofuran, Wako Pure Chemical Industries, Ltd, $99.5 \%$ ) solution under sonication for $2 \mathrm{~h}$ in $\mathrm{N}_{2}$ and then the THF solution was evaporated at room temperature in $\mathrm{N}_{2}$ to leave $\mathrm{Pt}-\mathrm{Ru}$ on the carbon support. The reduction of prepared $\mathrm{Pt}-\mathrm{Ru} / \mathrm{C}$ was carried out at $350{ }^{\circ} \mathrm{C}$ under a pure hydrogen flow for $3 \mathrm{~h}$. The Pt and Ru contents of Pt-Ru/CNTs were estimated to be 19 wt\%Pt-7 wt\%Ru/defect-free CNTs, 25 wt\%Pt-7 wt\%Ru/defective CNTs and 25 wt\%Pt-7 wt\%Ru/fishbone-type CNTs, as measured by ICP (inductively coupled plasma emission spectrograph), respectively. A commercial 20 wt\%Pt-10 wt\%Ru/VulcanXC-72R catalyst (Johnson Matthey) was also tested for comparison.

Catalysts were tested for electrochemical MOR activity in a three-electrode glass cell in $1 \mathrm{~mol} \mathrm{dm}^{-3} \mathrm{CH}_{3} \mathrm{OH}+0.05 \mathrm{~mol} \mathrm{dm}^{-3} \mathrm{H}_{2} \mathrm{SO}_{4}$ at fixed temperatures between $20{ }^{\circ} \mathrm{C}$ and $60{ }^{\circ} \mathrm{C}$. Catalysts were loaded on a glassy carbon disk electrode $\left(0.28 \mathrm{~cm}^{2}\right)$ with $5 \mathrm{wt} \%$ Nafion solution (Aldrich) diluted with methanol (1:50). The working electrode was the catalyst supported glassy carbon disk, the counter electrode was platinum plate and a reversible hydrogen electrode (RHE) was used as the reference electrode.

The catalytic performance was further tested in a single fuel cell configuration in a DMFC mode. Membrane electrode assemblies (MEAs) having active areas of $4 \mathrm{~cm}^{2}$ were made to test the catalysts in a fuel cell. The catalyst ink was prepared by mixing 30 mg of Pt-Ru/CNTs with $500 \mathrm{mg}$ of $5 \mathrm{wt} \%$ Nafion solution (Aldrich) and $0.1 \mathrm{~cm}^{3}$ of ethanol, which was then pasted on a carbon paper (TORAY TGP-H-090). Anode was loaded with 19 wt\%Pt-7 wt\%Ru/defect-free CNTs, 25 wt\%Pt-7 wt\%Ru/defective CNTs, 25 wt\%Pt-7 wt\%Ru/fishbone-type CNTs and 20 wt\%Pt-10 wt\%Pt-Ru/VulcanXC-72R 
catalysts on carbon paper, each with $0.36 \mathrm{mg}(\mathrm{Pt}) \mathrm{cm}^{-2}, 0.4 \mathrm{mg}(\mathrm{Pt}) \mathrm{cm}^{-2}, 0.56 \mathrm{mg}(\mathrm{Pt})$ $\mathrm{cm}^{-2}$ and $0.7 \mathrm{mg}(\mathrm{Pt}) \mathrm{cm}^{-2}$, respectively, and the cathode was loaded with $20 \% \mathrm{Pt} / \mathrm{C}$ on carbon paper (1 mg(Pt) $\mathrm{cm}^{-2}$, ElectroChem) for each MEA. MEA was prepared by hot-pressing the anode and the cathode catalyst-loaded carbon paper $\left(2 \times 2 \mathrm{~cm}^{2}\right)$ to each side of the Nafion 115 membrane at the pressure of $100 \mathrm{MPa}$ at $135{ }^{\circ} \mathrm{C}$ for 3 minutes.

The cell temperature was 30, 60, and $80{ }^{\circ} \mathrm{C}$ and $10 \mathrm{w} \%$ methanol and oxygen gas were fed to the anode and cathode chambers with flow rate of 5 and $100 \mathrm{~mL} \mathrm{~min}^{-1}$, respectively.

Oxidation of pre-adsorbed carbon monoxide $\left(\mathrm{CO}_{\mathrm{ad}}\right)$ was measured by $\mathrm{CO}_{\mathrm{ad}}$ stripping voltammogram in $0.05 \mathrm{~mol} \mathrm{dm}{ }^{-3} \mathrm{H}_{2} \mathrm{SO}_{4}$ solutions at $60{ }^{\circ} \mathrm{C}$ at a scan rate of $10 \mathrm{mV} \mathrm{s}^{-1}$. CO gas was passed into the cell for $30 \mathrm{~min}$ to allow complete adsorption of CO onto the electrocatalysts. Then excess $\mathrm{CO}$ was purged with $\mathrm{N}_{2}$ gas for $30 \mathrm{~min}$.

The crystallographic and morphological structures of Pt-Ru/defect-free CNTs, Pt-Ru/defective CNTs, Pt-Ru/fishbone CNTs and Pt-Ru/VulcanXC-72R were characterized by X-ray diffraction (XRD, Phillips, X`pert MPD) and transmission electron microscopy (TEM, JEOL, JEM-2010F).

\section{Results and discussion}

BET specific surface areas were 72.7, 105.5, 90.6, and $206.6 \mathrm{~m}^{2} \mathrm{~g}^{-1}$ for defect-free, defective CNTs, fishbone-type CNTs and VulcanXC-72R, respectively. The defective CNTs were prepared by oxidation to examine the effect of carbon surface.

Figure 1 shows the current density-potential curves of MOR measured for Pt-Ru/defect-free CNTs at $20-60{ }^{\circ} \mathrm{C}$. With elevating the temperature, the activities of MOR for Pt-Ru/defect-free CNTs are enhanced, and the MOR peak top shifted depending on the temperature. The result clearly shows a strong temperature 
dependence of MOR.

Figure 2 shows the Arrhenius plots of the currents, from which the activation energy of MOR was estimated to be $31.5,30.5$, and $29.1 \mathrm{~kJ} \mathrm{~mol}^{-1}$ at potentials $0.45,0.5$, and $0.55 \mathrm{~V}$, respectively. The value agreed with reported results by Lee et al. for Pt-Ru catalysts supported on HOPG [12]. The change of activation energy of MOR with the potential may be ascribed to a variation in the coverage of adsorbates $(\mathrm{CO}$ and $\mathrm{OH})$ on Pt sites with the potential. Table 1 summarizes the activation energy of MOR of Pt-Ru catalysts using different carbon supports. The activation energy of MOR for Pt-Ru catalysts at $0.55 \mathrm{~V}$ vs. RHE was estimated to be 29.1, 37.4, 45.0 and $32.6 \mathrm{~kJ} \mathrm{~mol}^{-1}$, for defect-free CNTs, defective CNTs, fishbone-type CNTs and VulcanXC-72R, respectively. The activation energy for Pt-Ru/defect-free CNTs exhibited the lowest values among other Pt-Ru catalysts. The Vulcan XC-72 support also showed low activation energies. This result indicates that the catalytic activity of MOR depends on significantly on the carbon substrate materials.

Table 2 summarizes the MOR performance of various carbon substrate materials for Pt-Ru catalysts at $60{ }^{\circ} \mathrm{C}$. In view of the current density at the overpotential of $0.4 \mathrm{~V}$ vs. RHE, Pt-Ru/defect-free CNTs showed four times higher current density than Pt-Ru/VulcanXC-72R. The potential value at current density of $1 \mathrm{~mA} \mathrm{~cm}{ }^{-2}$ in the polarization curve was $0.34 \mathrm{~V}$ vs. RHE for Pt-Ru/defect-free CNTs. The value is lower than Pt-Ru/VulcanXC-72R by about $0.04 \mathrm{~V}$. It is thus indicated that the carbon substrate materials affect the polarization behavior of MOR remarkably, and that defect-free CNTs largely improves the MOR activity of Pt-Ru electrocatalysts.

Polarization curves (at 30, 60, and $80{ }^{\circ} \mathrm{C}$ ) of DMFC with different anode catalyst support are shown in Figure 3. For the Pt-Ru/defect-free CNTs, in the activation-controlled region (i.e., at $0.4 \mathrm{~V}$ ) the current density changed from 16.1 to 128 
$\mathrm{mA} \mathrm{cm}{ }^{-2}$ as the cell temperature rose from 30 to $80{ }^{\circ} \mathrm{C}$, revealing a strong temperature dependence. In addition, the Pt-Ru/defect-free CNTs catalyst of $0.36 \mathrm{mg}(\mathrm{Pt}) \mathrm{cm}^{-2}$ afforded higher DMFC performances at all the current densities, compared with the Pt-Ru/VulcanXC-72R catalyst, even though the catalysts loading was half that of Pt-Ru/VulcanXC-72R (0.7 $\left.\mathrm{mg}(\mathrm{Pt}) \mathrm{cm}^{-2}\right)$. The open circuit voltage (OCV) of the cell with Pt-Ru/defect-free CNT was $0.73 \mathrm{~V}$ in comparison to $0.69 \mathrm{~V}$ with Pt-Ru/Vulcan XC-72R. The potential value at the current density of $200 \mathrm{~mA} \mathrm{~cm}^{-2}$ was $0.38 \mathrm{~V}$ vs. RHE for Pt-Ru/defect-free CNTs, which was much higher than that of the Pt-Ru/VulcanXC-72R (0.33 V). The peak power densities for Pt-Ru/defect-free CNTs, Pt-Ru/defective CNTs, Pt-Ru/fishbone-type CNTs and Pt-Ru/VulcanXC-72R recorded at $80{ }^{\circ} \mathrm{C}$ were $78,62,62$, and $65 \mathrm{~mW} \mathrm{~cm}^{-2}$ at current densities of 328, 306, 285, and 327 $\mathrm{mA} \mathrm{cm}{ }^{-2}$, respectively. It is concluded the Pt-Ru/defect-free CNTs have the higher catalytic activity of MOR and the higher power density than the other three $\mathrm{Pt}-\mathrm{Ru} / \mathrm{carbon}$ electrodes. The high power density of the Pt-Ru/CNTs electrode seems to be of great advantage for the application to various devices.

In order to investigate on the effect of carbon substrate materials on the catalytic activity of MOR and the performance of DMFC, the $\mathrm{CO}_{\mathrm{ad}}$ stripping voltammograms were conducted in $0.05 \mathrm{~mol} \mathrm{dm}{ }^{-3} \mathrm{H}_{2} \mathrm{SO}_{4}$ at $60{ }^{\circ} \mathrm{C}$. The $\mathrm{CO}_{\mathrm{ad}}$ oxidation process plays a crucial role in the MOR process [13]. Figure 4 shows the $\mathrm{CO}_{\mathrm{ad}}$ stripping voltammograms of $\mathrm{Pt}-\mathrm{Ru}$ catalysts on various carbon substrate materials. A $\mathrm{CO}_{\mathrm{ad}}$ oxidation peak of Pt-Ru catalyst is observed at 0.38, 0.4, 0.39 and $0.43 \mathrm{~V}$ vs. RHE for defect-free CNTs, defective CNTs, fishbone-type CNTs and VulcanXC-72R, respectively. Kawaguchi et al. have reported that the $\mathrm{CO}$ oxidation peak of the $\mathrm{Pt}-\mathrm{Ru} / \mathrm{C}$ pyrolyzed at various temperatures appeared at 0.45 to $0.465 \mathrm{~V}$ vs. RHE [14]. For all the samples used this work, the CO oxidation peak appeared at lower potentials as 
compared to $\mathrm{Pt}-\mathrm{Ru} / \mathrm{C}$. In addition, the peak potential of the $\mathrm{CO}_{\mathrm{ad}}$ oxidation on Pt-Ru/defect-free CNTs was about $0.05 \mathrm{~V}$ lower, with a smaller CO oxidation current compared to Pt-Ru/VulcanXC-72R. The lower potential and smaller current of CO oxidation for Pt-Ru/defect-free CNTs might be attributed to the unique morphology structure and electric properties of the CNTs (higher electric conductivity than that of VulcanXC-72R), although detailed mechanism awaits further studies [15].

Figure 5 shows the typical TEM images and the histograms of the particle size estimated from 100 particles for Pt-Ru catalysts supported on various carbon substrates. The average sizes of Pt-Ru particles measured by the TEM observation were $7.7,8.4$, 13.1 and $2.0 \mathrm{~nm}$ for Pt-Ru/defect-free CNTs, Pt-Ru/defective CNTs, Pt-Ru/fishbone-type CNTs and Pt-Ru/Vulcan XC-72R, respectively. Pt-Ru particles with the size 2 to $15 \mathrm{~nm}$ were well dispersed on carbon substrate materials. No significant differences to explain the support effect were found by the TEM observation. Furthermore, as shown in Fig. 6, XRD results indicated the formation of Pt-Ru alloy for all the Pt-Ru catalysts. Again, any significant differences among the measured samples were not identified by XRD, except for the smaller crystallite sizes for Pt-Ru/Vulcan XC-72R than for other catalyst samples.

It was found that the surface composition of Pt-Ru nanoparticles determined by the XPS measurement varied depending on carbon substrate materials. The surface compositions of $\mathrm{Pt}-\mathrm{Ru}$ catalysts were $\mathrm{Pt}_{62} \mathrm{Ru}_{38}, \mathrm{Pt}_{47} \mathrm{Ru}_{53}$, and $\mathrm{Pt}_{82} \mathrm{Ru}_{18}$ for defect-free CNTs, fishbone-type CNTs and VulcanXC-72R, respectively. These results suggested that the composition of Pt-Ru nanoparticles changed due to the carbon surface state. Watanabe et al. reported the maximum catalytic activity of $\mathrm{Pt}-\mathrm{Ru} / \mathrm{C}$ catalysts for the oxidation of methanol occurred at the equi-atomic composition of $\mathrm{Pt}_{50} \mathrm{Ru}_{50}$ [1]. However, Hubert et al. have reported the optimum surface had a Ru content which increased with 
increasing temperature, from close to 10 atomic percent $\mathrm{Ru}$ at $25{ }^{\circ} \mathrm{C}$ to a value in the vicinity of 40 atomic percent at $60{ }^{\circ} \mathrm{C}$ [16]. It is thus considered that the surface composition of Pt-Ru nanoparticles may be a crucial factor for the MOR.

Although the detailed MOR mechanisms are not clear for Pt-Ru/defect free-CNTs, we found here that the MOR and the performance of DMFC of Pt-Ru anode catalysts varied significantly depending on the carbon supports. Two possible reasons for the support effect of CNTs for DMFC can be proposed based on the different reactivity of flat graphene surfaces and the edges of graphene sheets. First, the composition of Pt-Ru may be different between flat and edged graphene surfaces, because it is considered that the flat surface structure of CNTs consisting of graphene sheet influences the composition of Pt-Ru nano particles as XPS measurement suggested. Second, the chemical effect at the interface between the catalyst particles and the carbon surface may cause different catalytic activities through electron transfer processes [17].

\section{Conclusions}

The support effect of carbon nanotubes (CNTs) for direct methanol fuel cell (DMFC) was examined by electrochemical MOR measurements, DMFC performance and CO stripping voltammograms. MOR and DMFC performances showed that the Pt-Ru catalysts supported on defect-free CNTs revealed the highest catalytic activity among $\mathrm{Pt}-\mathrm{Ru} / \mathrm{C}$ tested. $\mathrm{CO}$ stripping voltammogram also showed that the $\mathrm{CO}$ oxidation peak varied depending on the carbon substrate materials, where that of Pt-Ru/defect-free CNTs occurred at the lowest potential. The highest catalytic activity of MOR and DMFC for Pt-Ru/defect-free CNTs was suggested to be a result of the CO oxidation activity due to the carbon surface states. The results of the present work suggest the importance of the electrical properties, morphology, and crystallographic structures of 
the carbon support materials. 
Figure captions

Figure 1 Linear sweep voltammograms for methanol oxidation on Pt-Ru/defect-free CNTs in $1 \mathrm{~mol} \mathrm{dm}^{-3} \mathrm{CH}_{3} \mathrm{OH}+0.05 \mathrm{~mol} \mathrm{dm}^{-3} \mathrm{H}_{2} \mathrm{SO}_{4}$ solution at various temperatures. Sweep rate: $0.01 \mathrm{~V} \mathrm{~s}^{-1}$

Figure 2 Arrhenius plots of MOR current densities on Pt-Ru/defect-free CNTs

Figure 3 Current-potential curves of DMFC for Pt-Ru anode catalysts. (a) Pt-Ru/defect-free CNTs (0.36 mg(Pt) $\mathrm{cm}^{-2}$ ), (b) Pt-Ru/defective CNTs (0.40 mg(Pt) $\mathrm{cm}^{-2}$ ), (c) Pt-Ru/fishbone-type CNTs (0.56 mg(Pt) $\mathrm{cm}^{-2}$ ) and (d) Pt-Ru/Vulcan XC-72R (0.7 mg(Pt) $\mathrm{cm}^{-2}$ ). Cathode: $1 \mathrm{mg}(\mathrm{Pt}) \mathrm{cm}^{-2}$ (20 wt\%, Pt/C. E-TEK), membrane: Nafion ${ }^{\circledR}$ 115, cell temperature: $\mathbf{\square}: 30^{\circ} \mathrm{C}$ :60 ${ }^{\circ} \mathrm{C} \boldsymbol{\Delta}: 80{ }^{\circ} \mathrm{C}$, methanol concentration: 10 w\%.

Figure $4 \mathrm{CO}$ stripping voltammograms of the Pt-Ru catalysts for different carbon materials in $0.05 \mathrm{~mol} \mathrm{dm}^{-3} \mathrm{H}_{2} \mathrm{SO}_{4}$. (a) defect-free CNTs, (b) fishbone-type CNTs, (c) defective CNTs, and (d) Vulcan XC-72R. Sweep rate: $0.01 \mathrm{~V} \mathrm{~s}^{-1}$

Figure 5 The TEM images of Pt-Ru/Carbon and the histogram of Pt-Ru particle size. (a) Pt-Ru/defect-free CNTs, (b) Pt-Ru/defective CNTs, (c) Pt-Ru/fishbone-type CNTs, and (d) Pt-Ru/Vulcan XC-72R

Figure 6 XRD pattern for (a) Pt-Ru/defect-free CNTs, (b) Pt-Ru/defective CNTs, (c) Pt-Ru/fishbone-type CNTs, and (d) Pt-Ru/Vulcan XC-72R 


\section{References}

[1] M. Watanabe, M. Uchida, S. Motoo, J. Electroanal. Chem., 229 (1987) 395-406.

[2] T. J. Schmidt, H.A. Gasteiger, R.T. Behm, Electrochem. Commun., 1 (1999) 1-4.

[3] Y. Takasu, T. Kawaguchi, W. Sugimoto, Y. Murakami, Electrochim. Acta., 48 (2003) 3861-3868.

[4] J. Prabhuram, T.S. Zhao, Z.K. Tang, R. Chen, Z.X. Liang, J. Phys. Chem. B., 110 (2006) 5245-5252.

[5] K.-A. H. Shijun, H. Tsaprailis, V.I. Briss, J. Am. Chem. Soc., 128 (2006) 3504-3505.

[6] T. Matsumoto, T. Komatsu, K. Arai, T. Yamazaki, M. Kijima, H. Shimizu, Y. Takasawa, J. Nakamura, Chem. Comm., 7 (2004) 840-841.

[7] T. Matsumoto, Y. Nagashima, T. Yamazaki, J. Nakamura, Electrochemical and Solid-state Letters., 9 (2006) A160-A162.

[8] E.J. Yoo, T. Okada, T. Kizuka, J. Nakamura, Electrochemistry., 2 (2007) 146-148.

[9] W. Li, X. Wang, Z. Chen, M. Waje, Y. Yan, J. Phys. Chem. B., 110 (2006) 15353-15358.

[10] C. Kim, Y.J. Kim, Y.A. Kim, T. Yanagisawa, K.C. Park, M. Endo, M.S. Dresselhaus, J. Appl. Phys., 96 (2004) 5903-5905.

[11] E.Yoo, L. Gao, T. Komatsu, N. Yagai, K. Arai, T. Yamazaki, K. Matsuishi, T. Matsumoto, J. Nakamura, J. Phys. Chem. B., 108 (2004) 18903-18907

[12] C.H. Lee, C.W. Lee, D.I. Kim, S.E. Bae, J. Hydrogen Energy., 27 (2002) 445-450.

[13] T. Kawaguchi, W.Sugimoto, Y. Murakami, Y. Takasu, J. Catal., 229 (2005) 176-184.

[14] J. O’M. Bockris, H. Wroblowa, J. Electroanal. Chem., 7 (1964) 428-451. 
[15] C.Y. Du, T.S. Zhao, Z.X. Liang, J. Power Sources 176 (2008) 9-15.

[16] A.G. Hubert, M. Nenad, N.R. Philip, J.C. Elton, J. Phys. Chem., 98 (1994) 617-625.

[17] K.S. Han, O.H. Han, and P.K. Babu, J. Electrochem. Soc., 152 (2005) J131-J135. 
Table 1 Activation energy of MOR for Pt-Ru/carbon

\begin{tabular}{ccccc}
\hline \multirow{2}{*}{ Potential /V vs. RHE } & \multicolumn{4}{c}{ Activation energy/ kJ mol ${ }^{-1}$} \\
\cline { 2 - 5 } & defect-free CNTs & defective CNTs fishbone-type CNTs & Vulcan XC-72R \\
\hline 0.45 & 31.5 & 41.5 & 49.6 & 25.9 \\
0.5 & 30.5 & 39.1 & 46.9 & 31.2 \\
0.55 & 29.1 & 37.4 & 45.0 & 32.6 \\
\hline
\end{tabular}


Table 2 Electrochemical performance of Pt-Ru catalysts supported on various carbon substrate materials at $60^{\circ} \mathrm{C}$

\begin{tabular}{ccc}
\hline Carbon support & $\mathrm{Ln}\left(\mathrm{I} / \mathrm{mA} \mathrm{cm}^{-2}\right)_{0.4 \mathrm{~V}}$ & $\mathrm{E}\left(\mathrm{I}=1 \mathrm{~mA} \mathrm{~cm}^{-2}\right) / \mathrm{V}$ vs. RHE \\
\hline defect-free CNTs & 2.1 & 0.34 \\
defective CNTs & 1.7 & 0.36 \\
fishbone-type CNTs & 1.8 & 0.36 \\
Vulcan XC-72R & 1.5 & 0.38 \\
\hline
\end{tabular}

$\mathrm{I}_{0.4 \mathrm{~V}}$ : current density at $0.4 \mathrm{~V}$ vs. RHE

$\mathrm{E}\left(\mathrm{I}=1 \mathrm{~mA} \mathrm{~cm}^{-2}\right)$ : potential at the current density $\mathrm{I}=1 \mathrm{~mA} \mathrm{~cm}^{-2}$ 


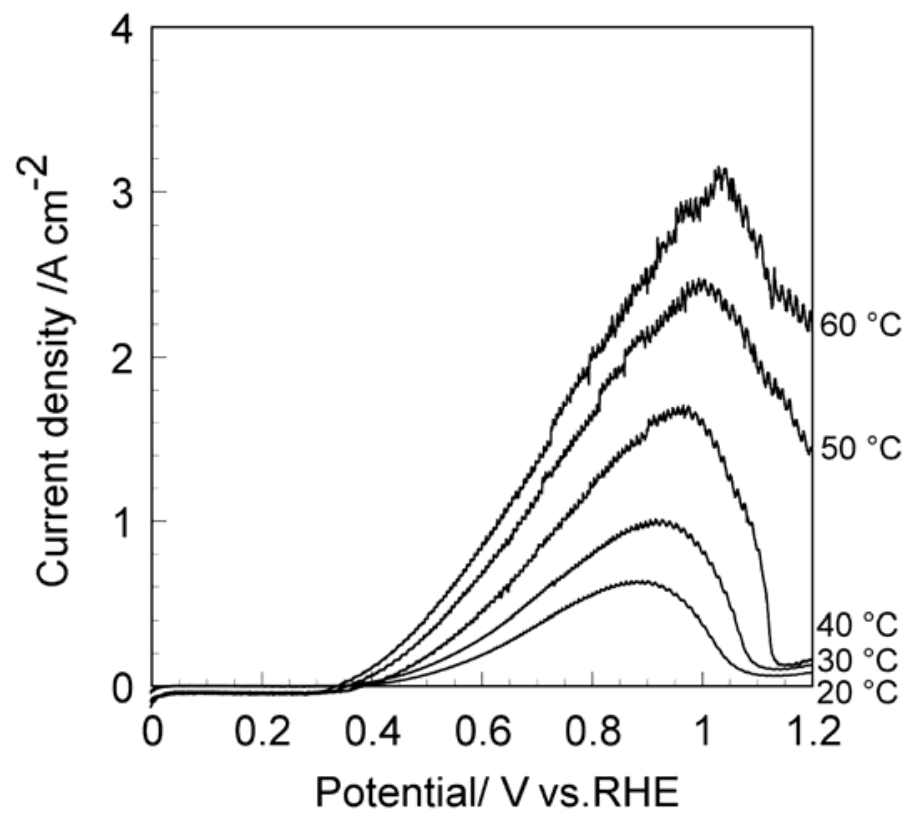

Fig 1. Yoo et al 


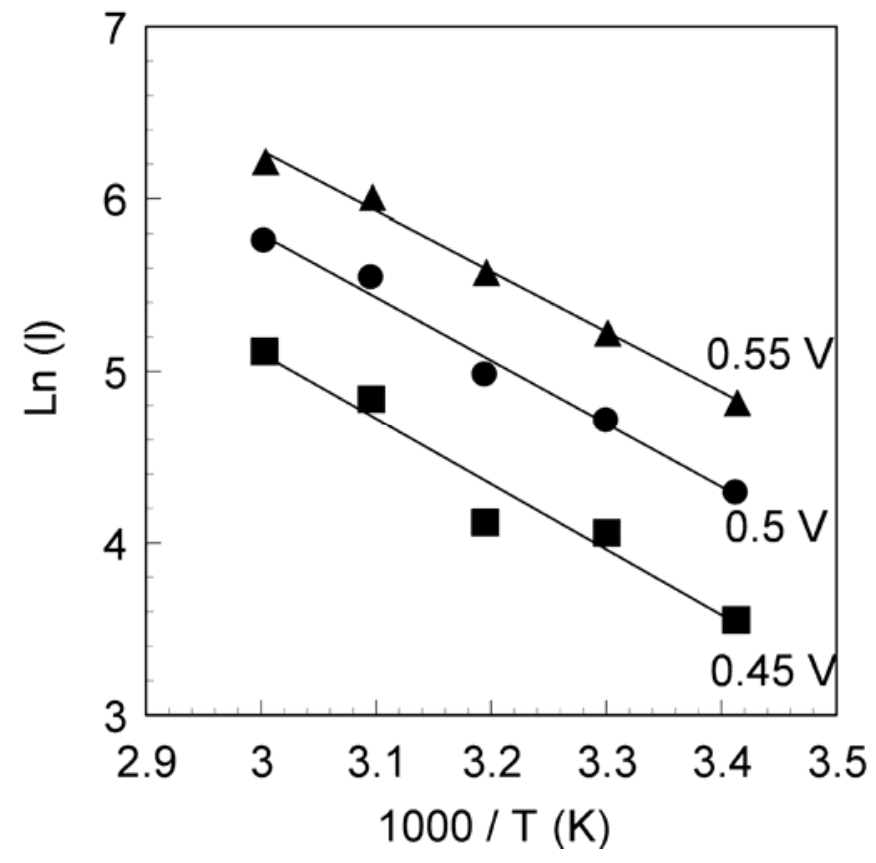

Fig 2 Yoo et al 

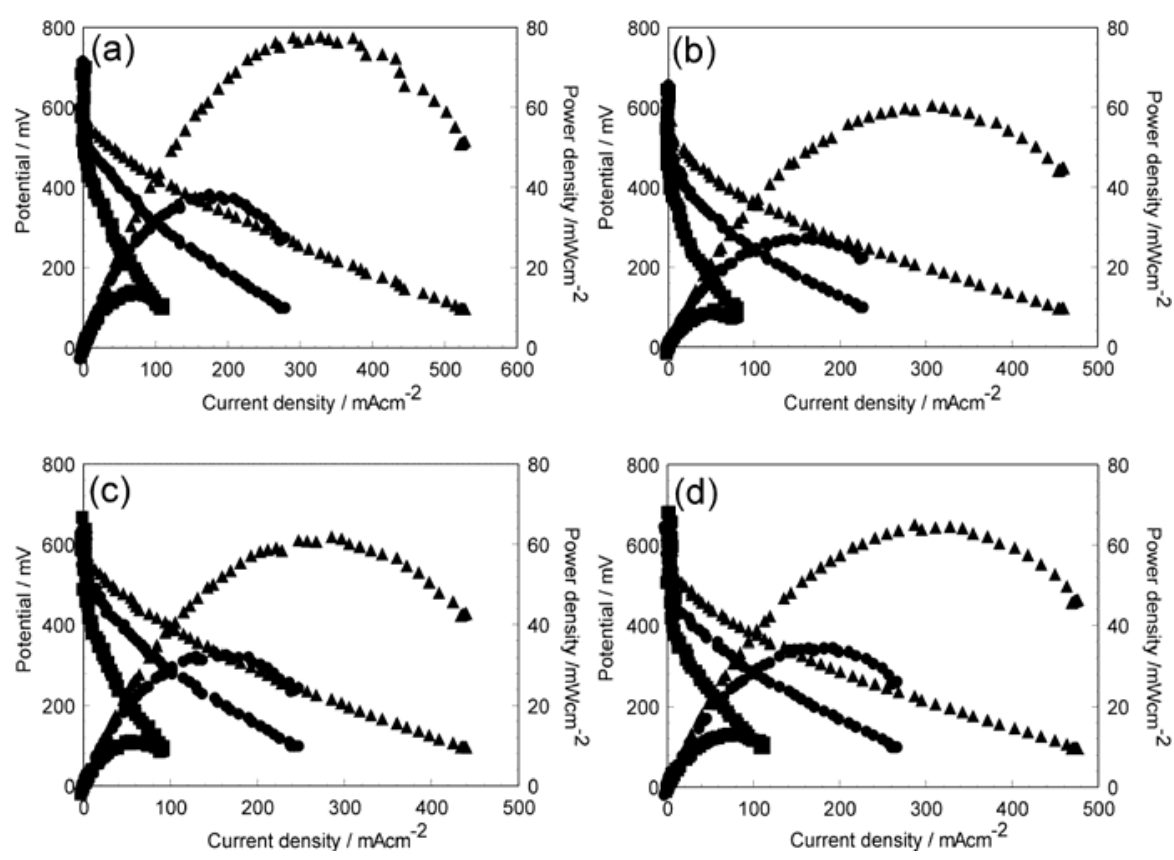

Fig 3 Yoo et al 


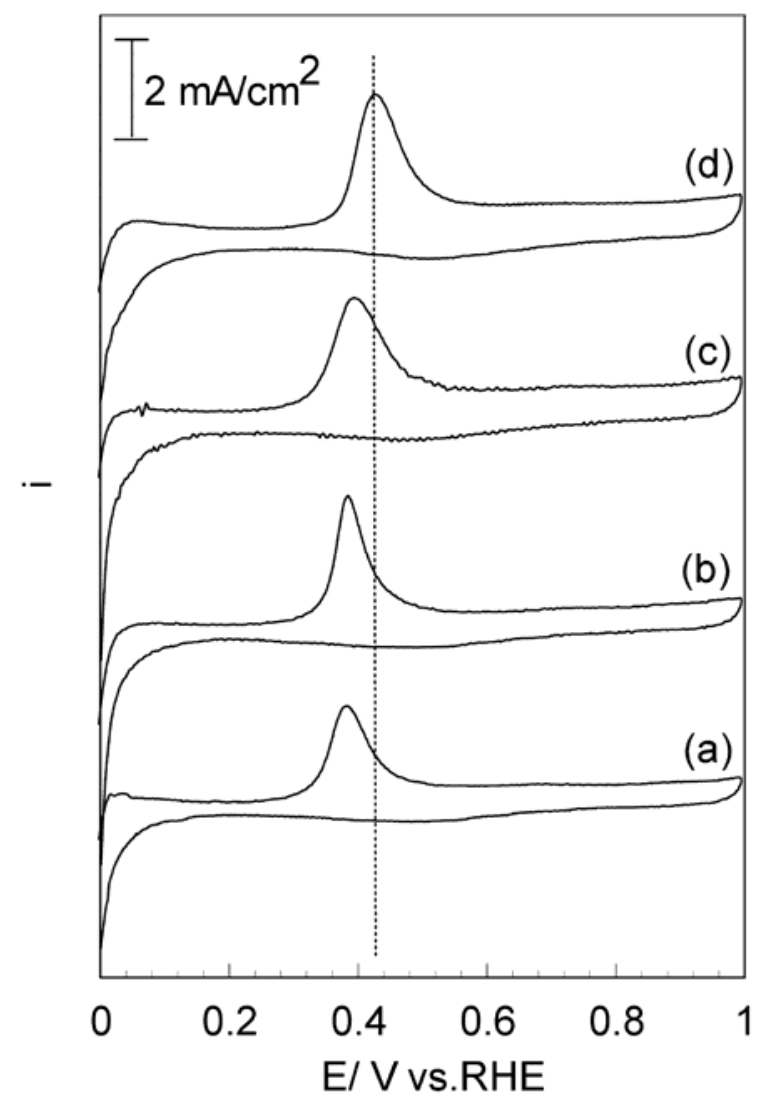

Fig 4 Yoo et al. 

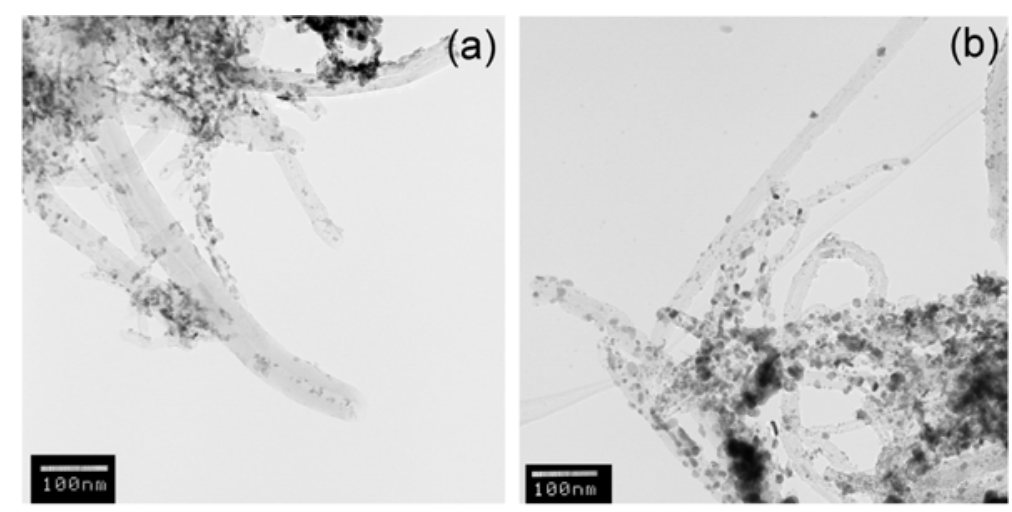

$\overline{100 \mathrm{~nm}}$

(c)

(d)
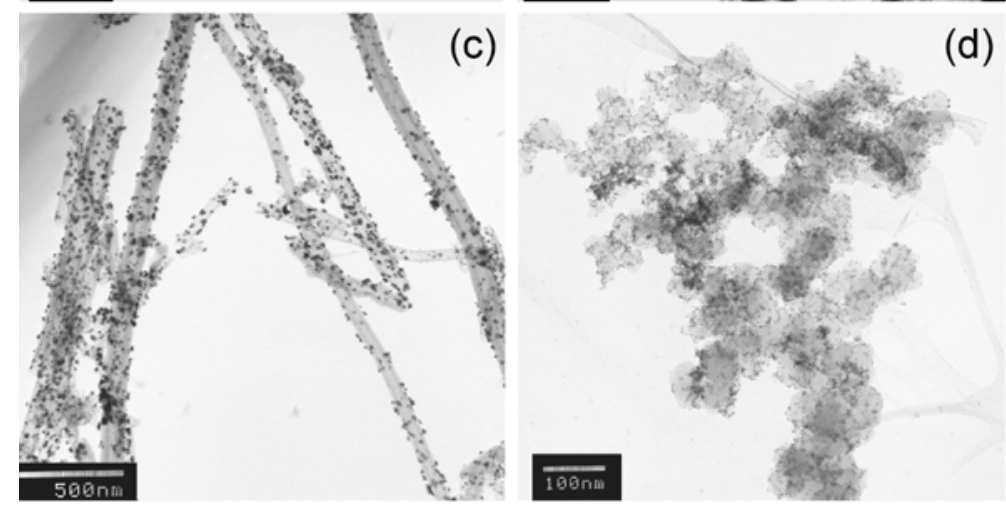

${ }^{50}$ (a)

(b)
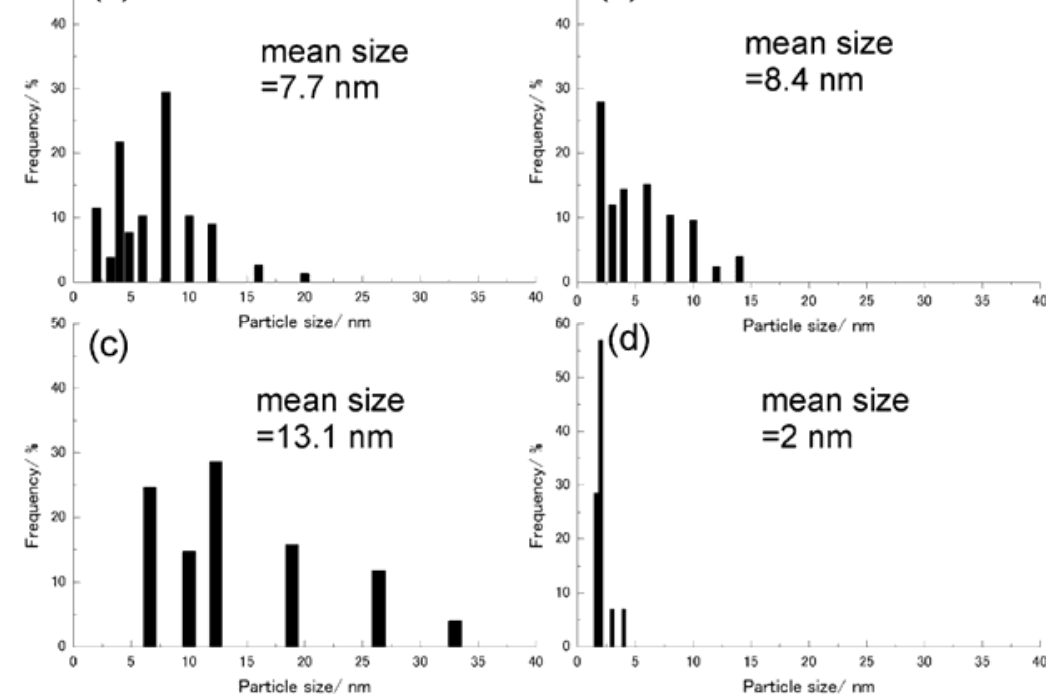

Fig 5 Yoo et al. 


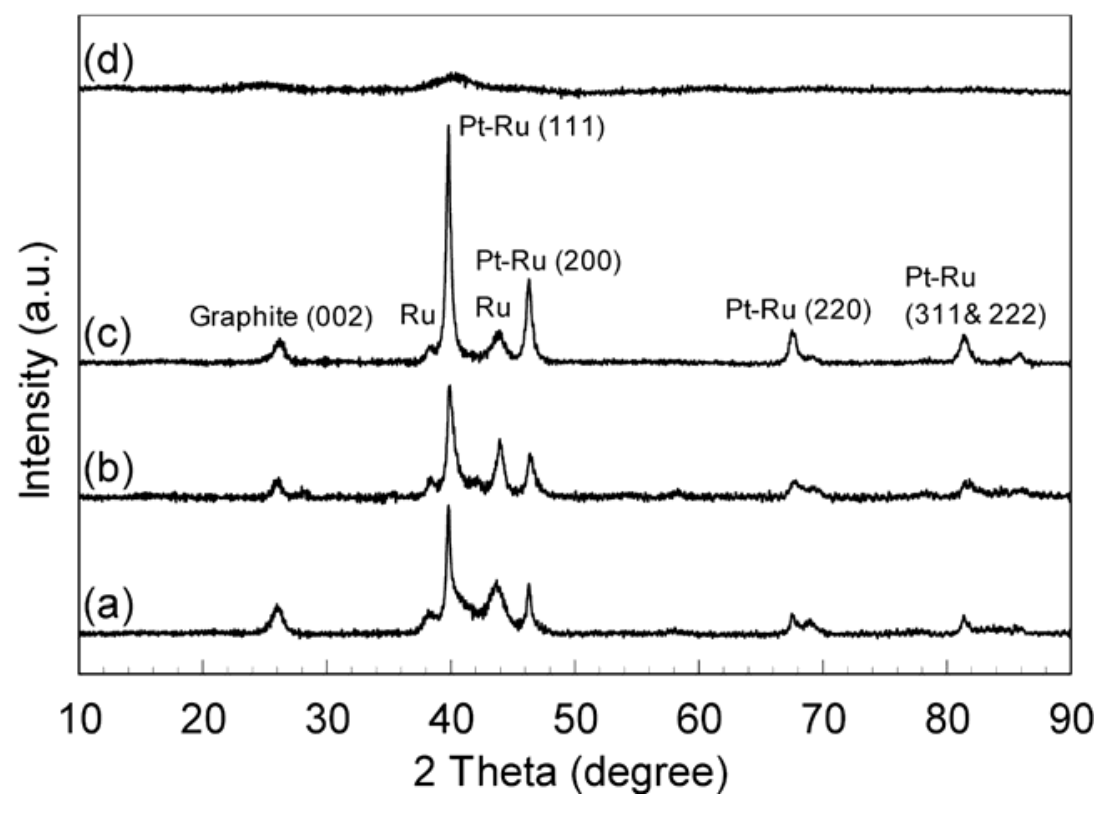

Fig 6 Yoo et al. 